\title{
Dexamethasone enhances risk of herpes zoster in severe COVID-19 infection
}

\author{
Nathan B. Price ${ }^{1} \cdot$ Charles Grose $^{2}(\mathbb{0}$
}

Received: 10 December 2021 / Accepted: 15 December 2021 / Published online: 22 December 2021

(c) The Author(s) 2021

We read the review article about herpes zoster and COVID19 infection with great interest [1]. As an example from the review, the author noted that the Brazilian Ministry of Health had documented an increase in cases of herpes zoster from 9.69 to 14.13 cases per million people in the Rio de Janeiro region pre-and post-COVID-19 epidemic. We propose that we can answer the question whether this association is a coincidence or a causal relationship, at least in several of the severe treated cases. There is a 70-year history in the medical literature about the induction of herpes zoster in a wide variety of patients who were prescribed corticosteroid therapy. We have recently reviewed this association [2]. This association has been documented in both immunocompetent and immunodeficient children and both immunocompetent and immunodeficient adults [3].

Dexamethasone has become commonplace in the treatment protocols for management of more severe cases of COVID-19 infection [4]. A standard dexamethasone dosage is $6 \mathrm{mg}$ per day for 10 days. The consensus in the virology literature is that a daily prednisone dosage of $20 \mathrm{mg}$ enhances the likelihood of herpes zoster in any adult [2]. The dexamethasone/prednisone equivalence between a daily dexamethasone dosage of $6 \mathrm{mg}$ is approximately $37 \mathrm{mg}$ of prednisone, almost twice the known risk dosage of $20 \mathrm{mg}$. Even smaller dosages of prednisone (7. $5 \mathrm{mg}$ daily, equivalent to $\sim 1 \mathrm{mg}$ dexamethasone) have been associated with increased herpes zoster in immunocompromised adults [2, 3]. Furthermore, prednisone has a half-life around $24 \mathrm{~h}$ whereas dexamethasone has a longer half-life. Thus, dexamethasone

Charles Grose

Charles-grose@uiowa.edu

1 Division of Infectious Diseases, Department of Pediatrics, University of Arizona, Tucson, AZ, USA

2 Division of Infectious Diseases/Virology Laboratory, Department of Pediatrics, University of Iowa Hospital, Room BT2001, 200 Hawkins Drive, Iowa City, IA 52242, USA given on a daily basis may accumulate to higher levels over the usual COVID-19 treatment period of 10 days.

When we performed a search on the Pubmed website, looking for articles on dexamethasone treatment of COVID19 , we retrieved 788 titles. A brief survey of these articles included an estimation that during 2020, as many as 50\% of patients with severe COVID-19 disease received corticosteroids. For example, in a large controlled open-label trial carried out in the United Kingdom by the Recover Collaborative Group, the investigators concluded that the use of dexamethasone resulted in a lower 28-day mortality among COVID-19 patients who were receiving either invasive mechanical ventilation or oxygen alone at randomization [5]. Finally, the guidelines of the Infectious Disease Society of America also recommend dexamethasone therapy for critically ill and severe but not critically ill cases of COVID-19 infection.

As cited in the review [1], most patients developed herpes zoster between 1 to 4 weeks after the diagnosis of COVID19 infection, the average being 17 days. One case occurred 2 days before diagnosis and another case occurred on the same day of diagnosis. Obviously, herpes zoster cases that occurred before or at the time of diagnosis of COVID-19 infection cannot be caused by dexamethasone, but the evidence in the medical literature strongly suggests that cases of herpes zoster that occur between 1 and 8 weeks after corticosteroid therapy can be secondary to the lymphopenia caused by corticosteroids [2,3]. To define a comprehensive hypothesis, we propose that COVID-19 infection by itself can on some occasions cause sufficient lymphopenia to lead to herpes zoster before onset of clinical COVID-19 infection. But more commonly we propose that the additive effect of dexamethasone-induced lymphopenia on COVID19-induced lymphopenia leads to the increased rate of herpes zoster after diagnosis and treatment of COVID-19 infection. Finally, we note that the majority of herpes zoster cases occurred in COVID-19 patients who were older than 
50 years and therefore already at higher risk to develop herpes zoster.

Acknowledgements Both NBP and CG are members of the Infectious Diseases Society of America.

Funding Research by CG on varicella-zoster virus is supported by grant number AI153817 from the National Institutes of Health, USA.

\section{Declarations}

Conflict of interest The authors have no relevant financial or non-financial interests to disclose.

Ethics approval This article is a review of published articles. Ethics approval is not relevant.

Open Access This article is licensed under a Creative Commons Attribution 4.0 International License, which permits use, sharing, adaptation, distribution and reproduction in any medium or format, as long as you give appropriate credit to the original author(s) and the source, provide a link to the Creative Commons licence, and indicate if changes were made. The images or other third party material in this article are included in the article's Creative Commons licence, unless indicated otherwise in a credit line to the material. If material is not included in the article's Creative Commons licence and your intended use is not permitted by statutory regulation or exceeds the permitted use, you will need to obtain permission directly from the copyright holder. To view a copy of this licence, visit http://creativecommons.org/licenses/by/4.0/.

\section{References}

1. Algaadi SA. Herpes zoster and COVID-19 infection: a coincidence or a causal relationship? Infection. 2021. https://doi.org/ 10.1007/s15010-021-01714-6.

2. Price NB, Grose C. Corticosteroids contribute to serious adverse events following live attenuated varicella vaccination and live attenuated zoster vaccination. Vaccines (Basel). 2021;9:23.

3. Marra F, Lo E, Kalashnikov V, Richardson K. Risk of herpes zoster in individuals on biologics, disease-modifying antirheumatic drugs, and/or corticosteroids for autoimmune diseases: a systematic review and meta-analysis. Open Forum Infect Dis. 2016;3: ofw05.

4. Hasan SS, Capstick T, Ahmed R, Kow CS, Mazhar F, Merchant HA, Zaidi STR. Mortality in COVID-19 patients with acute respiratory distress syndrome and corticosteroids use: a systematic review and meta-analysis. Expert Rev Respir Med. 2020;14:1149-63.

5. Horby P, Lim WS, Emberson JR, Mafham M, Bell JL, Linsell L, Staplin N, Brightling C, Ustianowski A, Elmahi E, Prudon B, Green C, Felton T, Chadwick D, Rege K, Fegan C, Chappell LC, Faust SN, Jaki T, Jeffery K, Montgomery A, Rowan K, Juszczak E, Baillie JK, Haynes R, Landray MJ. Dexamethasone in hospitalized patients with Covid-19. N Engl J Med. 2021;384:693-704. 